\title{
Review
}

\section{Powder Metallurgy Research and Development Activities at USTB}

\author{
Xuanhui Qu and Xinbo He \\ Beijing Key Laboratory for Advanced Powder Metallurgy and Particulate Materials, University of Science and Technology Beijing, \\ Beijing, 100083, P.R. China.
}

Received July 2, 2003

\begin{abstract}
SYNOPSIS
University of Science and Technology Beijing (USTB) is one of the key universities that are directly under the guidance of China Ministry of Education. Powder metallurgy activities have been carried out at USTB for about 50 years. Beijing Key Laboratory for Advanced Powder Metallurgy and Particulate Materials, which was founded on the base of Department of Powder Metallurgy at USTB, is a comprehensive base for PM education, research and development in China. In this paper, some of the current research activities and achievements in this laboratory are introduced, including ultra-fine grained cemented carbides made from nanometer powders, $\mathrm{W}-\mathrm{Cu}$ and $\mathrm{Mo}-\mathrm{Cu}$ alloys for electronic packages, SHS process and its applications, warm compaction, and powder injection molding.
\end{abstract}

KEY WORDS

overview, powder metallurgy, USTB

\section{Introduction}

Beijing Key Laboratory for Advanced Powder Metallurgy and Particulate Materials was founded in 2001 on the basis of Department of Powder Metallurgy at USTB under the joint supervision and support of Beijing Municipal Education Commission and Science \& Technology Commission. PM education and research activities have been carried out at USTB since its foundation in 1952. And now there are about 20 faculties and staff, as well as over 40 Master and Ph. D students in the Lab, including 6 full professors and 2 associated professors. In addition to supervising research activities in the Lab, the faculties provide several courses related to PM, such as Principles and Processing of Powder Metallurgy, Composite Materials, Advanced Materials Synthesis Technology and Processing, for under-graduated and post-graduated students in The School of Materials Science and Engineering at USTB. Researches conducted in the Lab concern basically the advanced PM processing, the structure and properties of various particulate materials. Special emphases have been put on the development of net-shape forming techniques and synthesis of nanometer powder as well as metal-matrix composites. Fundings of our research projects come from a variety of sources, including National Key Basic Research (973) Program, High Tech Research and Development (863) Program, National Science
Foundation of China, National Advanced Materials Program for Defence, R\&D program of Beijing Municipal and industry companies. Our research facilities which include advanced processing equipments and state-of-theart instruments are highly regarded among universities within our country. The high-lights of research in the recent years are introduced in the following paragraphs.

\section{Ultra-fine Grained WC-Based Cemented Carbides ${ }^{1,2)}$}

A novel processing for making ultra-fine grained cemented carbides was developed, with which high performance WC-based cemented carbides have been fabricated successfully. As one of the features of this process, a tailored nontoxic aqueous solution containing $\mathrm{W}$ and $\mathrm{V}$ was prepared, from which ultra-fine tungsten oxide powders could be synthesized through an ultrasonic spray conversion dryer. The tungsten oxide powders were in an amorphous state and with mean particle size of smaller than $50 \mathrm{~nm}$. They could be reduced and carbonized at lower temperature $\left(\leq 1200^{\circ} \mathrm{C}\right)$ compared with those produced with traditional process. Therefore, the produced WC powders were very small and with spherical shape as seen in Fig. 1. The average particle size was only about $100 \mathrm{~nm}$. In addition, because some $V$ was added in the solution, the carbonized powder contained some VC which would act 


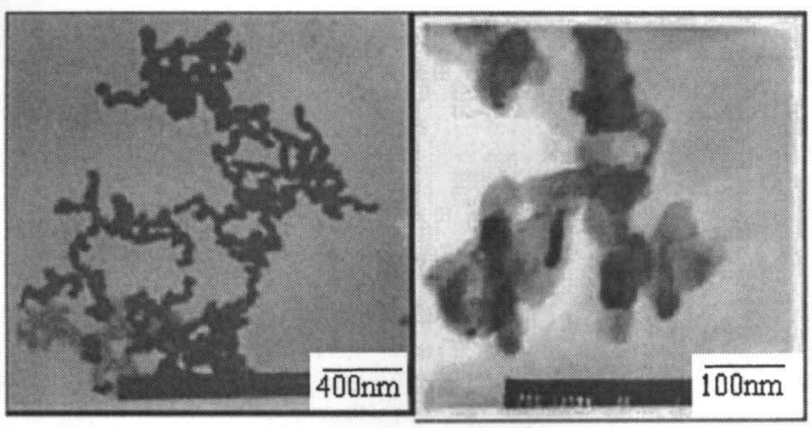

Fig.1 SEM micrographs of nano-meter WC powders.

as a grain-growth inhibitor during sintering. This process has been evaluated in a kilogram scale.

A WC-Ni-Fe alloy system was selected for the application research of the ultra-fine tungsten carbide powder in order to save Co and reduce the materials cost. The WC powders, after being pulverized in an attrition ball mill, were mixed with nano-sized $\mathrm{Ni}(\mathrm{Fe})$ powders which were also made with the above mentioned ultrasonic spray conversion process from a solution containing $\mathrm{Ni}$ and $\mathrm{Fe}$. The mixture was compacted and sintered in a sinter-HIPing furnace. The sintered WC-Ni-Fe cemented carbide showed full density and uniform microstructure with the WC grain size of only $300-500 \mathrm{~nm}$. The transverse-rupture-strength and hardness of the alloy were $3500 \mathrm{Mpa}$ and HRA93 respectively.

\section{$3 \mathrm{~W}-\mathrm{Cu}$ and Mo-Cu Alloys ${ }^{3-6)}$}

W-Cu and Mo-Cu alloys are widely used as heat-sink in electronic packages because of their low thermal expansion coefficient and high thermal conductivity. Usually they are produced with a sintering-infiltration process because it is very difficult to get fully dense $\mathrm{W}-\mathrm{Cu}$ and $\mathrm{Mo}-\mathrm{Cu}$ alloys with traditional press-sintering process from mixed powders due to the mutual insolubility or negligible solubility between the constituents. However, the complexity of the components which can be produced with sintering-infiltration process is very limited. A mechanical activation process was studied for $\mathrm{W}-\mathrm{Cu}$ and $\mathrm{Mo}-\mathrm{Cu}$ alloys in our Lab. The $\mathrm{W}$ or Mo powders were mechanically alloyed with $\mathrm{Cu}$ powders in a self-designed high-energy vibrating ball mill. At the beginning stage of milling, both the tungsten and molybdenum particles become finer rapidly, while the copper particles become sheet form. After milling for 3 hours, the particle size was reduced from about $4.8 \mu \mathrm{m}$ to smaller than $1 \mu \mathrm{m}$. The fine $\mathrm{W}$ and Mo particles were uniformly distributed in the copper sheets and

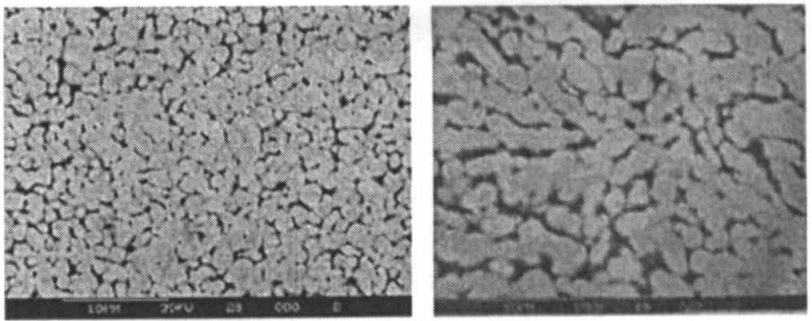

Fig.2 SEM of Microstructure of sintered W-15\% Cu (a) and Mo$38 \% \mathrm{Cu}$ alloys (b).

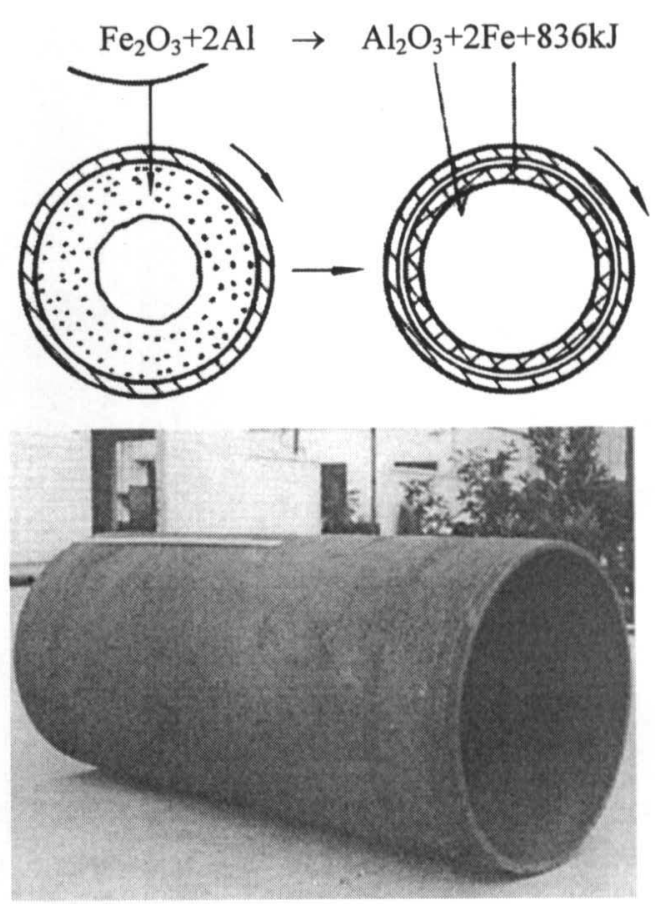

Fig.3 SHS-Centrifugal Process $(\Phi 820 \times 2000 \mathrm{~mm})$.

surrounded by copper. The milled powders were then pressed respectively into compacts with a relative density of about $65 \%$. For $\mathrm{W}-15 \% \mathrm{Cu}$ and Mo-38\%Cu alloys, after the compacts were sintered in a hydrogen atmosphere at $1340^{\circ} \mathrm{C}$ and $1230^{\circ} \mathrm{C}$ respectively, the relative density could go up to $98.5 \%$. Fig. 2 shows the microstructure of the sintered alloys. Their thermal conductivity was tested to be $182 \mathrm{~W} / \mathrm{m} . \mathrm{K}$ and $154 \mathrm{~W} / \mathrm{m} . \mathrm{K}$ respectively.

\section{SHS Process and its Applications ${ }^{7-9)}$}

In the late 1980 s, we began to study Self- propagation High-temperature Synthesis (SHS) or Combustion Synthesis (CS). Two kinds of SHS approaches (SHSCentrifugal process and SHS-Gravitational process) for the fabrication of ceramic-lined steel pipes have been successfully developed in our Lab. Fig. 3 and Fig. 4 show the principles of the two processes and the corresponding products respectively. 

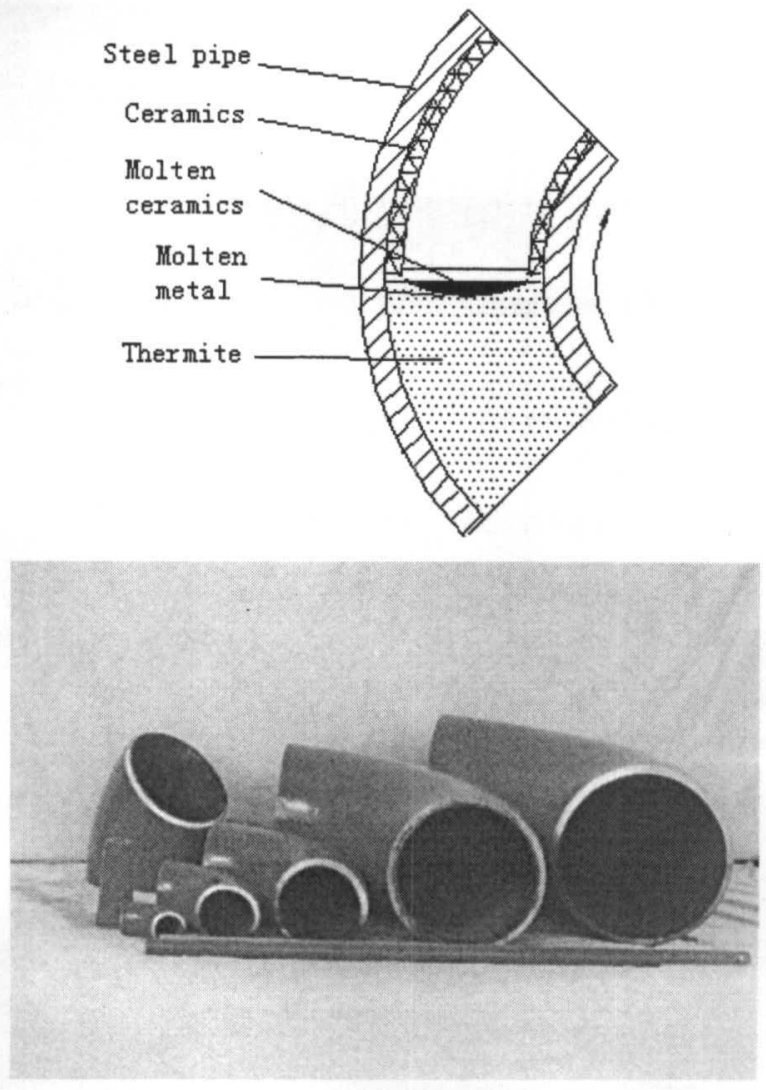

Fig.4 SHS-Gravitational process $(\Phi 10-325 \mathrm{~mm})$.

The ceramic-lined steel pipes made by SHS process displayed superior properties in wear resistance, corrosion resistance, thermal and mechanical shock resistance, which have been industrially applied to transport coal, coke, coal cinder, mineral powder, cement mortar, molten aluminum and oil-water. The service life of the ceramic lined steel pipes are several to tens times longer than those of conventional steel pipes. A great variety of standard ceramic-lined steel linear pipes, elbows, three-way or fourway pipes $(\phi 10 \sim \phi 820 \mathrm{~mm})$ can be manufactured in a large scales in China.

Recently, a new project was started in this research group to identify the feasibility to make porous Ni-Ti shape memory alloys for biomedical implanting materials and to

$$
\mathrm{Fe}_{2} \mathrm{O}_{3}+2 \mathrm{Al} \rightarrow \mathrm{Al}_{2} \mathrm{O}_{3}+2 \mathrm{Fe}+836 \mathrm{~kJ}
$$

process nuclear fuel wastes with SHS technique. The results are very promising. The porous $\mathrm{Ni}-\mathrm{Ti}$ components with a porosity of $40 \% \sim 72 \%$ and a compressive strength of 40 $\sim 220 \mathrm{Mpa}$ can be synthesized by SHS. An synthesized porous sample and its microstructure are presented in Fig. 5. In the approach to immobilize nuclear fuel wastes with peroviskite $\left(\mathrm{CaTiO}_{3}\right)$, chromium oxide was selected as the

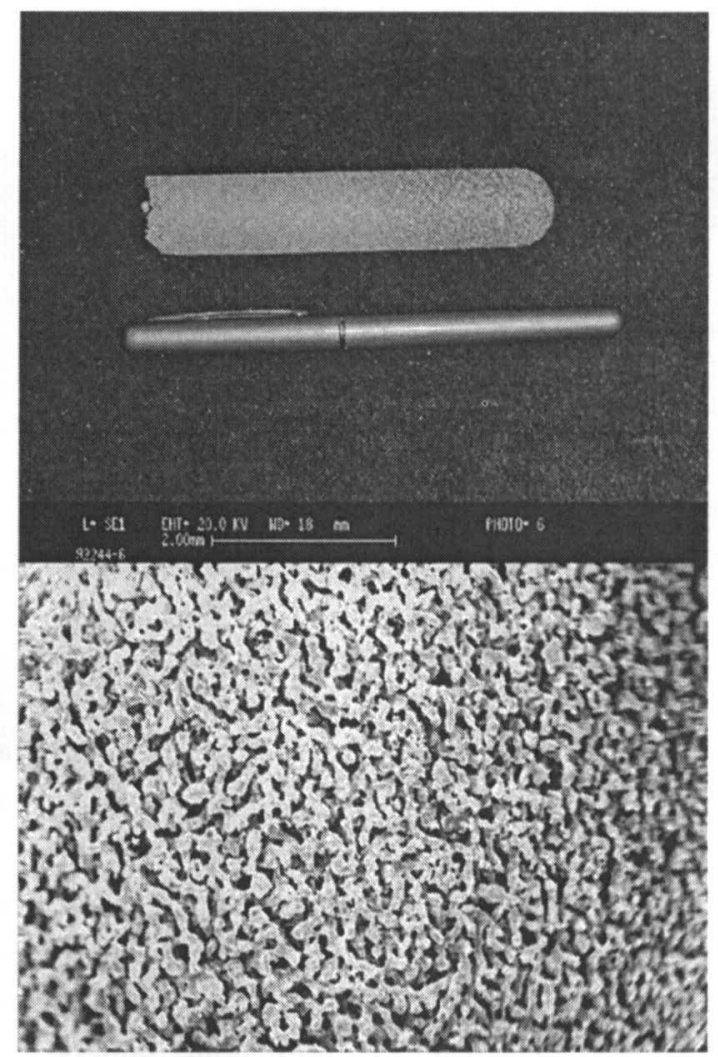

$\begin{array}{ll}\text { (a) sample } & \text { (b) SEM of the alloy }\end{array}$

Fig.5 Porous NiTi shape memory alloy component and its microstructure.

oxidant in the SHS reaction with $\mathrm{Ti}, \mathrm{CaO}$ and $\mathrm{TiO}_{2}$ to form peroviskite. It was proved that over $35 \%$ of $\mathrm{SrO}$ could be immobilized in peroviskite with the SHS method.

\section{Warm Compaction and Enhanced Sintering of Ferrous-based Alloys ${ }^{10-12)}$}

Warm compaction technique has been studied in this Lab since 1996. The emphases were put on the development of die-wall lubrication technique, selection of lubricants, and enhancement of sintering for ferrous-based alloys and composites. The electrostatic die-wall lubrication technique was tested for the warm compaction. The results showed that pure zinc stearate could be easily charged, while the other lubricants, including EBS wax, W-special wax and various mixtures of zinc stearate with EBS wax, could not be charged until the charging voltage reached to a critical value as seen in Fig. 6. Fig. 7 compared the densities of 316L stainless steel powder compacts pressed with conventional pressing and warm compaction at different pressure levels. Warm compaction could increase the density by $0.2-0.5 \mathrm{~g} / \mathrm{cm}^{3}$. A master alloy (FeMoB) with low melting point was prepared and studied for enhancing 


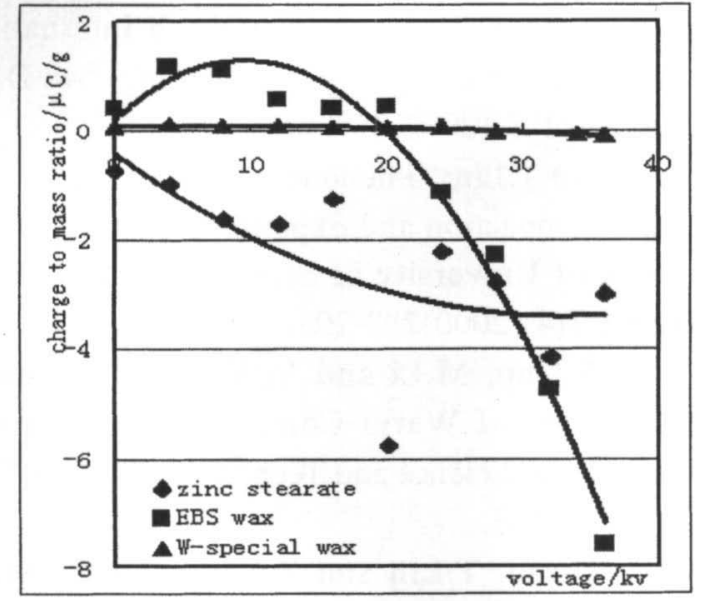

Fig.6 Relationships between charge to mass ratio and charging voltage for various lubricants.

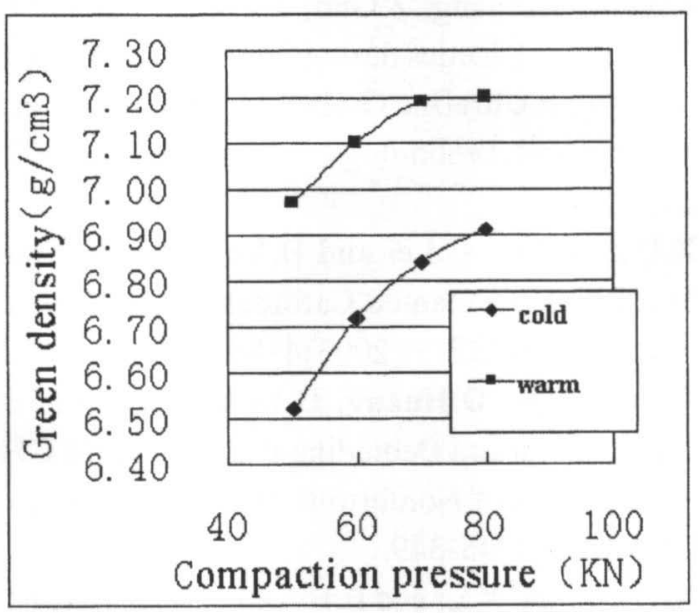

Fig.7 Comparison of green density of $316 \mathrm{~L}$ stainless steel powder compacts pressed with different methods.

sintering process through forming liquid phase during sintering. It was determined that the $316 \mathrm{~L}$ stainless steel powder compacts could be sintered to the density of $98 \%$ by addition of the master alloy.

\section{Powder Injection Molding ${ }^{13-17}$}

Powder injection molding (PIM) is a manufacturing process used in the fabrication of net- or near-net-shape components with highly controlled microstructures and properties. It can be used in the production of both metallic and non-metallic components. In our lab, several new binder systems as well as the debinding techniques have been invented and successfully used to fabricate $\mathrm{Fe}-\mathrm{Ni}$, Kovar, stainless steel, tungsten heavy alloys, cemented carbides, titanium and AlN ceramic components. Most of components have been put into market and widely used in

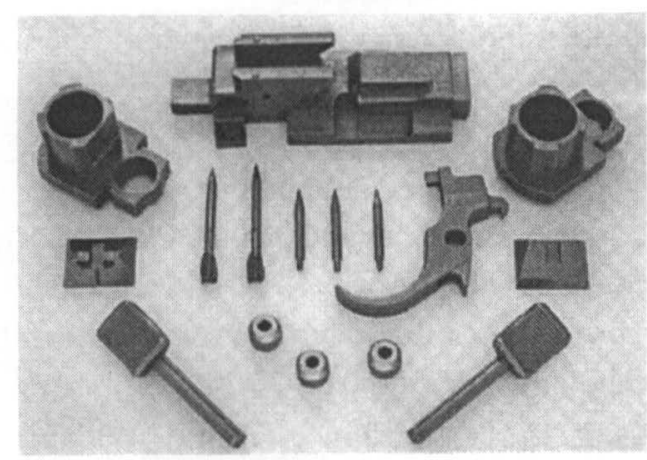

Fig.8 Examples of PIM components.

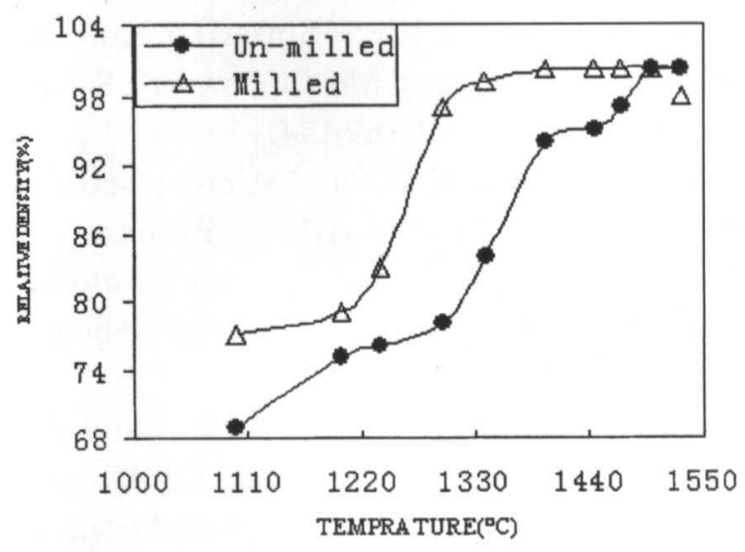

Fig.9 Variation of density with sintering temperature.

defense and civil sectors in China. Fig. 8 showed some of the produced components. Simulation technology for diefilling process of powder injection molding was developed based on ANSYS, with which the flow front, temperature, pressure and residue stress fields in the compacts could be calculated and shown dynamically by computer. It is very useful for guiding the mold cavity design and selection of processing parameters. In addition, chaos and fractal theory are being used to study PIM process. The enhanced sintering of tungsten heavy alloy compacts was investigated in order to make tungsten heavy alloy components with less distortion. Solid-state sintering to almost full density for W-Ni-Fe was realized with the nano-grained composite powder made by mechanical alloying as seen in Fig. 9, which showed potential for eliminating distortion caused by gravity during liquid phase sintering.

\section{Acknowledgement}

The authors wish to express their most sincere thanks to Professor Sheng Yin, Professor Shiju Guo, Professor Chengchang Jia, Professor Liying Zhang, Professor Zhimeng Guo, Dr. Tao Lin and Dr. Mingli Qin, who 
provided the reference for this article and gave valuable advice.

\section{References}

(1) H.Yan, L.Zhang, C.Wu; Q.Wu and P.Cui: "Ultrafine Hard Alloy Powders of WC-Fe-Ni Prepared by Direct Carbonization Process", Powder Metallurgy Technology, 19(3)(2001)144-147.

(2) J.Wang, L.Zhang, Z.Guo, T.Lin, C.Wu and Q.Wu: "Shrinkage Kinetics during Sintering W-Ni-Fe Heavy Alloy with Ultrafine Grain", Journal of University of Science and Technology Beijing, 24(2)(2002)107.

(3) C.Jia, X.Li and Z.Xie: "Sintering Kinetics of Mechanically Activated Mo-Cu Powder", Science of Sintering, 31(3)(1999)169-174.

(4) C.Jia, X.Guan and X.Su: "Microstructure and Properties of W-Cu Alloys Prepared with Mechanically Activated Powder", Journal of University of Science and Technology Beijing, 8(2) (2001)129-132.

(5) C.Jia, Z.He, X.Su, Z.Yang, J.Zhao and Z.Xie: "Microstructures of Sintered Mo-Cu Alloys with Mechanically Activated Powder", Rare Metals, 20(2) (2001)112-116.

(6) C.Jia, X.Jin, J.Zhao and Z.Xie: "Preparing W-Cu Alloys by Mechanical and Chemical Activation Processes", Powder Metallurgy Technology, 19(3) (2001)148-152.

(7) S.Yin: "Combustion Synthesis", Beijing: Metallurgical Industry Press, (1999).

(8) T.Lin, S.Guo, S.Yin and Z.Guo: "Characteristics of Combustion Reaction in $\mathrm{Al}-\mathrm{Fe}_{2} \mathrm{O}_{3}$ System under Gravitational Field", Key Engineering Materials, 21(7) (2002)133-136.

(9) Z.Guo, C.Chen, F.Gao and S.Yin: "Ti-Ni Porous Alloy
Made by SHS Process", The Ninth International Conference on Composite Engineering, San Diego, USA, July1-7, (2002)259.

(10) S.Guo and T.Lin: "Phenomenological Modeling of Warm Compaction and Experimental Verification", Journal of University of Science and Technology Beijing, 7(4)(2000)292-295.

(11) T.Lin, S.Guo, M.Li and Y.Wei: "Densification Mechanism of Warm Compaction", Journal of University of Science and Technology Beijing, 22(2) (2000)131-133.

(12) M.Li, S.Guo, T.Lin and Z.Kang: "Influence of Characteristics of Iron Powders on Warm-Compacted Density", Powder Metallurgy Technology, 18(3) (2000) 172-177.

(13) J.Wang, L.Zhang, Z.Guo, T.Lin, C.Wu and Q.Wu: "Shrinkage Kinetics during Sintering W-Ni-Fe Heavy Alloy with Ultrafine Grain", Journal of University of Science and Technology Beijing, 24(2)(2002)107110.

(14) X.Qu, B.Zhu, C.Lei and B.Ye: "Powder Injection Molding of Cemented Carbides", Materials Science Forum, 426-432(5)(2003)4185-4190.

(15) J.Lin, X.Qu, D.Huang, D.Li and M.Qin: "Binder Composition and Debinding Process in PIM Of AIN", Transactions of Nonferrous Metals Society of China, 11(3)(2001)345-349.

(16) X.Qu, J.Fan, Y.Li and B.Huang: "Synthesis and Solid State Sintering of W-Ni-Fe Nano-Composite Powders", Acta Metallurgica Sinica (English Letters), 13(3)(2000)917-920.

(17) C.Jia, S.Fan, Y.Peng, X.Zhao and X.Lu: "Sintering Mechanism of Stainless Steel in Powder Injection Molding", Journal of University of Science and Technology Beijing, 7(1)(2000)51-54. 